\title{
The prevention and management of Frey's syndrome and a step by step guide through the nonsurgical treatment with Botulinum toxin
}

\author{
Lukas S Fiedler ${ }^{1}$ \\ ${ }^{1}$ Klinikum Mutterhaus der Borromaerinnen gGmbH
}

November 23, 2020

\begin{abstract}
Firstly described by Lucy Frey in 1923 the "Frey's syndrome" is characterized by sweating and flushing in direct response to mastication. The mechanism is aberrant regeneration of postganglionic parasympathetic neurons from the auriculotemporal nerve and Acetylcholine secretion by a masticatory stimulus. This entity occurs in up to $65 \%$ following lateral parotid resections and less commonly after neck dissection or facelift procedures. This article aims to list possible surgical and non-surgical treatment options of this iatrogenic entity but should focus on the treatment with botulinum toxin A and provide a step by step guide from the Lugol-Iodine-Starch test to the botulinum toxin A (BoNTA-ONA) injection within the affected area.
\end{abstract}

Lukas S. Fiedler ${ }^{1}$

${ }^{1}$ Otorhinolaryngology and head and neck surgery, Klinikum Mutterhaus der Borromäerinnen Mitte, Trier, Germany, Feldstraße 16, 54290 Trier, lukas.fiedler@mutterhaus.de

Manuscript type Practical tips and/or guidelines.

Conflicts of interest None.

Keywords Frey's syndrome, treatment, prevention, Botox, Botulinum Toxin, complication, parotid resection

\section{Introduction}

Frey's syndrome (syn. Auriculotemporal syndrome, gustatory sweating) is a postoperative phenomenon following lateral parotid resection in up to $65 \%[1]$, and less commonly neck dissection or facelift procedures. Firstly, described by Lucy Frey in 1923 it is characterized by sweating and flushing in direct response to mastication. The mechanism is aberrant regeneration of postganglionic parasympathetic neurons from the auriculotemporal nerve and Acetylcholine secretion by a masticatory stimulus. [2, 3] In Frey's syndrome, Acetylcholine diffuses to sweat glands in the skin and provokes sweating and/or dermal flush in the distribution of the auriculotemporal nerve. [3] Preparation of a thick skin flap and partial superficial parotidectomy is the most important techniques to reduce the risk of developing a Frey syndrome. [1] The dermal application of botulinum toxin A is an effective, long-lasting treatment of Frey syndrome and can be repeated if recurrent symptoms occur. $[2,4]$

This article aims to list possible surgical and non-surgical treatment options of this iatrogenic entity but should focus on the treatment with botulinum toxin A and provide a step by step guide from the LugolIodine-Starch test to the botulinum toxin A (BoNTA-ONA) injection within the affected area. 
Even though the botulinum toxin A injection is the prevailing method of treatment of Frey's syndrome, some authors suggest a benefit using dermofat grafts or special incision techniques, SMAS flaps, or the use of facelift approaches for the parotidectomy. [5-8]

\section{Botulinum toxin-Application-Step by step}

1. Lugol's solution (Iodine-potassium-iodide) is painted preauricular over the cheek, down to the neck and dries within two minutes.

2. Apply starch powder on the prepared area and provoke the sensory stimulus giving the patient sour drops or apple or tangerine.

3. The affected area reveals as shown in picture 1. Mark the blue demarked area and get rid of the powder using a disinfectant.

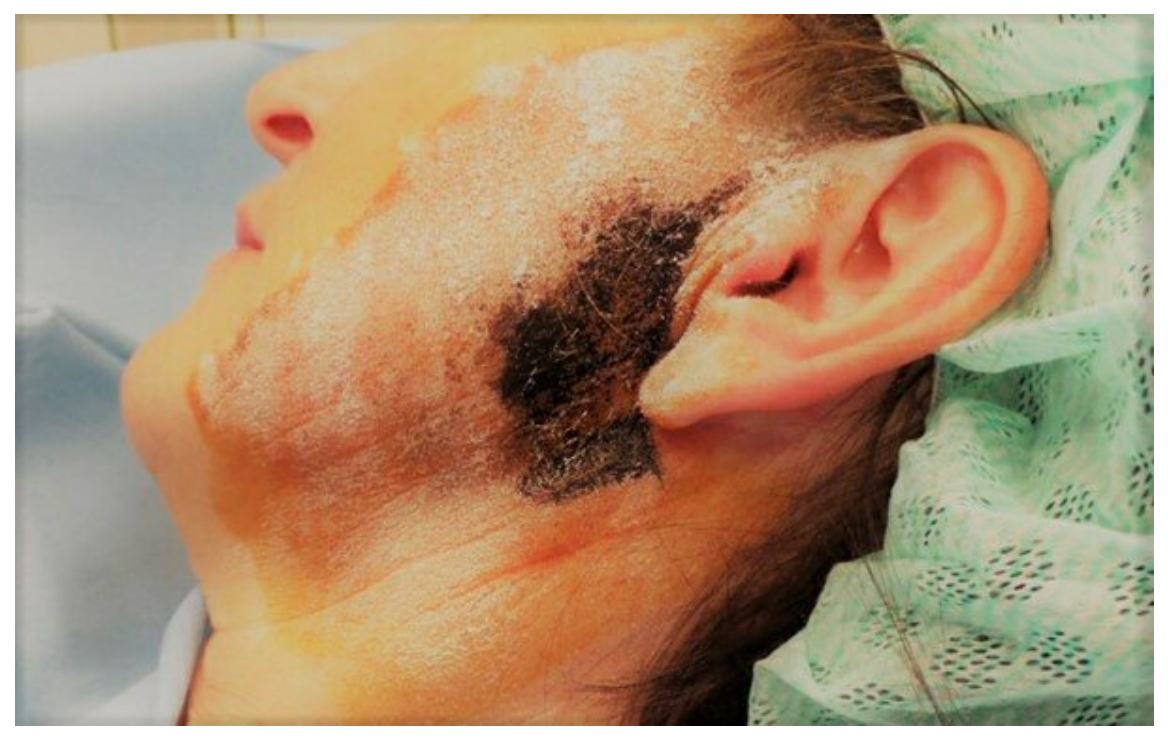

picture 1.

Divide the area in a $1 \mathrm{~cm}^{2}$ grid as shown in picture 2. This grid respects the diffusion halo of Botulinum toxin, which is dose depending and normally around 1,5 to 2,6 cm in diameter. [9] Further, an interinjection distance of one centimetre is recommended. [10] 


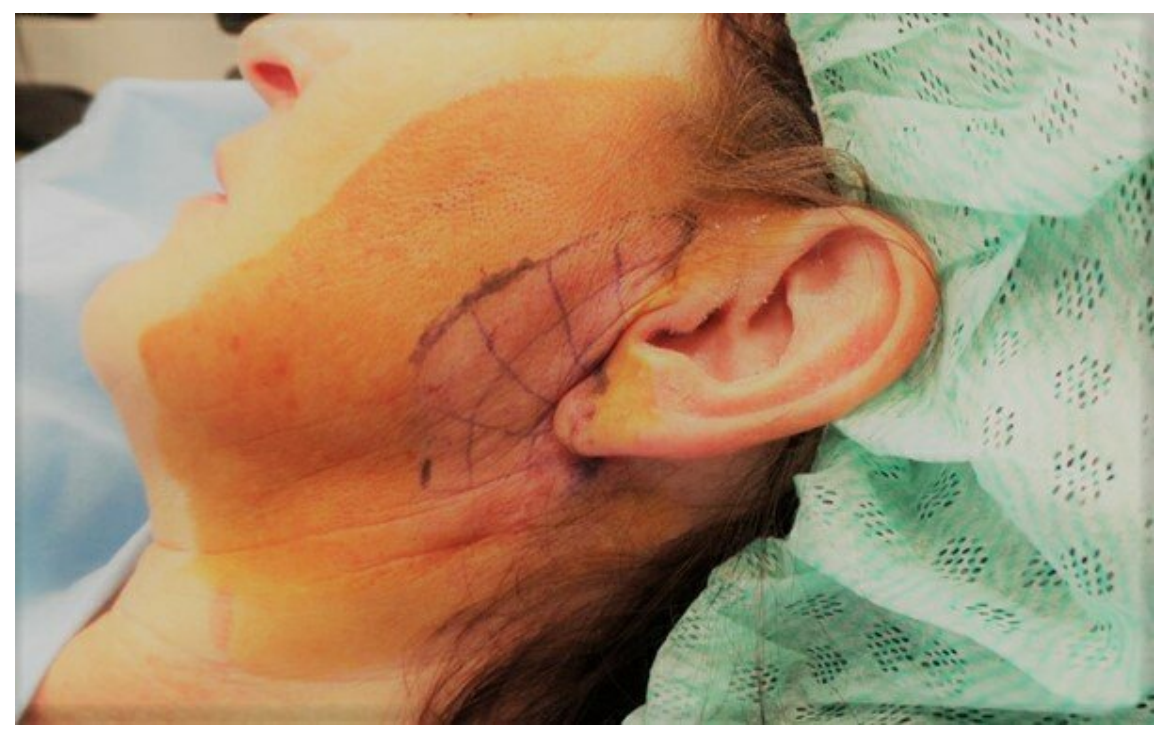

picture 2 .

Cool the area with a coolpad, alternatively apply topical or inject local anaesthetics. [2]

Now inject 3-5 BU (Botox Units) per $\mathrm{cm}^{2}$ in $0,1 \mathrm{~mL}$ solute. Therefore, inject superficially into the dermis. Weakening the facial mimetic muscles is unlikely if you not inject anterior to the front border of the masseter muscle. [2]

\section{Key aspects in the reduction of probability to establish symptomatic Frey's syndrome}

Intraoperatively, the prevention of synkinesis seems to be key, not affecting the superficial sweat glands and is done by increased skin flap thickness or using local fascia or muscle flaps. Therefore used flaps can be a transposition fascia flap, a temporoparietal fascia flap [11], a sternocleidomastoid muscle flap, and a superficial musculoaponeurotic system flap. [3, 12]

Further, the use of acellular dermal matrix (ADM)[13], the injection of polyglycolic acid[14], elevation of a vascularized fat flap[15] or free fat grafts (AFG) with abdominal free fat [8]can prevent symptomatic Frey's syndrome.[3]

\section{Confirmation of Frey's syndrome}

Confirmatory testing of symptomatic Frey's syndrome is routinely done by a Starch- Iodine-test with a gustative stimulus eg. Apple slices. $60 \%$ of patients who underwent lateral parotidectomy had a positive Starch- Iodine-test, whereas only $23 \%$ declared subjective symptoms. [3]

\section{Treatment options of Frey's syndrome}

Intradermal Botulinum injection reduces redding and sweating in the affected area and increases the quality of life; repeated injections are effective, but 27 to $92 \%$ of patients complain about recurrent symptoms in 1 to 3 years.[3]

Surgical therapy in established Frey's has a likely benefit, big cohorts and clinical data to support that is missing and should be questioned in prospective studies, further SMAS, SCM, or TPFF reconstruction increases the risk of facial nerve injury. $[3,11]$ 


\section{Take home messages}

- Frey's syndrome is a postoperative phenomenon following lateral parotid resection in up to $65 \%$

- Frey's syndrome is characterized by sweating and flushing in direct response to mastication

- Preparation techniques can be the key in the prevention of the Frey's syndrome

- Frey's syndrome is diagnosed by Starch- Iodine-test with a gustative stimulus

- Botulinum toxin A injection is the prevailing method of treatment of Frey's syndrome

\section{Disclosures}

The author declared no potential conflicts of interest concerning the research, authorship, and publication of this article.

\section{References}

1. Gillespie, M.B. and D.W. Eisele, CHAPTER 20 - Complications of Surgery of the Salivary Glands, in Complications in Head and Neck Surgery (Second Edition) , D.W. Eisele and R.V. Smith, Editors. 2009, Mosby: Philadelphia. p. 221-239.

2. Kontis, T.L., V., Neurotoxin Injection for Gustatory Sweating, in Cosmetic Injection Techniques: A Text and Video Guide to Neurotoxins and Fillers . 2013, Thieme: New York, Stuttgart. p. 74f.

3. Motz, K.M. and Y.J. Kim, Auriculotemporal Syndrome (Frey Syndrome). Otolaryngologic clinics of North America, 2016.49 (2): p. 501-509.

4. de Bree, R., I. van der Waal, and C.R. Leemans, Management of Frey syndrome. Head Neck, 2007. 29 (8): p. $773-8$.

5. Yoo, Y.M., et al., Dermofat graft after superficial parotidectomy via a modified face-lift incision to prevent Frey syndrome and depressed deformity. J Craniofac Surg, 2011. 22 (3): p. 1021-3.

6. Bianchi, B., et al., Improving esthetic results in benign parotid surgery: statistical evaluation of facelift approach, sternocleidomastoid flap, and superficial musculoaponeurotic system flap application. J Oral Maxillofac Surg, 2011. 69 (4): p. 1235-41.

7. Kim, I.K., et al., Facelift incision and superficial musculoaponeurotic system advancement in parotidectomy: case reports.Maxillofac Plast Reconstr Surg, 2015. 37 (1): p. 40.

8. Torretta, S., et al., Fat injections for the management of post-parotidectomy Frey syndrome: a technical note. J Craniomaxillofac Surg, 2012. 40 (2): p. 173-6.

9. Costa, A.P., E.; Pereira, M.; Santos, F.; Favaro, R.; Stocco, P.; Arruda, L., Comparative study of the diffusion of five botulinum toxins type-A in five dosages of use: Are there differences amongst the commerciallyavailable products? escholarship, 2012.

10. Guntinas-Lichius, O., Increased botulinum toxin type A dosage is more effective in patients with Frey's syndrome. Laryngoscope, 2002.112 (4): p. 746-9.

11. Dai, X.M., et al., Prevention of Frey Syndrome With Temporal Fascia Flap in Parotidectomy. Ann Plast Surg, 2015. 75 (6): p. 610-4.

12. Dulguerov, N., A. Makni, and P. Dulguerov, The superficial musculoaponeurotic system flap in the prevention of Frey syndrome: A meta-analysis. Laryngoscope, 2016. 126 (7): p. 1581-4. 
13. Choi, J., et al., Acellular dermal matrix (Insuregraf) in the prevention of Frey's syndrome and surgical site depression after parotidectomy. Arch Craniofac Surg, 2019. 20 (3): p. 176-180.

14. Aizawa, T., et al., Polyglycolic Acid Felt for Prevention of Frey Syndrome After Parotidectomy. Ann Plast Surg, 2018.81 (4): p. 438-440.

15. Ghassemi, A., et al., Vascularised fatty tissue: its role in prevention of the symptoms of Frey syndrome after parotidectomy. Br J Oral Maxillofac Surg, 2018. 56 (9): p. 877-880. 